\title{
Leitura e ensino de literatura na era dos textos multimodais ${ }^{1}$
}

\section{Reading and teaching Literature in the multimodal text era}

\author{
Eliana Cristina Scheuer ${ }^{2}$ \\ eliana_srl@hotmail.com \\ Eliza Adriana S. Nantes ${ }^{3}$ \\ eliza@unopar.br; nantes@uel.br
}

Rosemari Bendelin Calzavara ${ }^{4}$

calzavara@unopar.br

Resumo: Com as novas tecnologias digitais, a interação entre texto e leitor foi alterada pelo suporte e pela esfera de atividade humana, possibilitando significados diferentes, de acordo com a forma de apresentação do texto ou pela percepção individual do leitor (BAKHTIN, 2010). Diante disso, nesta sociedade na qual imperam os multiletramentos, defrontamo-nos com uma multiplicidade de gêneros discursivos, pertencentes as mais divergentes formas textuais (ROJO, 2013). Isso posto, o objetivo do presente trabalho é investigar a relação entre a leitura e a literatura, na era em que imperam os textos multimodais. Para tanto, procedeu-se a uma pesquisa qualitativa, na qual se procurou estabelecer um diálogo entre a leitura e o ensino da literatura, na escola pública, ensino médio, e o resultado desse contexto é o surgimento de um novo tipo de leitor, um leitor navegador, que apresenta hábitos distintos do leitor do texto impresso, que faz sua leitura linha/linha, página a página. O novo leitor navega em telas, saltando de link em link, interagindo entre textos, imagens, músicas, vídeos, jogos etc.

Palavras-chave: Leitura, Literatura, Textos multimodais

Abstract: With new digital technologies, the interaction between text and reader has been changed by the support and by the sphere of human activity, making possible different meanings, in accordance with the way the text is presented or by the individual perception of the reader (BAKHTIN, 2010). In this society, in which the multiple ways of writing are dominating, we face a multiplicity of discursive types, belonging to the most divergent textual forms (ROJO, 2013). The objective of the present work is to investigate the relation among the reading and the literature in an era in which the multimodal texts prevail. To achieve that, a qualitative inquiry was proceeded, in which a dialog was established among the reading and the teaching of literature, in public schools and secondary education. The result of said inquiry is the appearance of a new type of reader, a navigating reader, who presents habits that are different from those of the printed text reader, who does his reading line to line, page to page. The new reader navigates within seams, jumping from link to link, interacting texts, images, music, videos, games etc.

Keywords: Reading, Literature. Multimodals texts

\footnotetext{
${ }^{1}$ Agradecemos à Fundação Nacional de Desenvolvimento do Ensino Superior Particular (Funadesp) e a Comissão de Aperfeiçoamento de Pessoal do Nível Superior (Capes) pelo apoio à pesquisa.

${ }^{2}$ Mestre em Metodologias para o Ensino de Linguagens e suas Tecnologias (Unopar)

${ }^{3}$ Universidade Norte do Paraná (Unopar), Doutora em Estudos da Linguagem (UEL)

${ }^{4}$ Universidade Norte do Paraná (Unopar), Doutora em Literatura (UEL)
}

Revista Educação Online, n. 19, jun-ago 2015, p. 20-44 


\section{Introdução}

Dentro da perspectiva dos multiletramentos, a questão da leitura se encontra permeada por diversas modalidades de linguagem, por conseguinte, 0 ato de ler ultrapassa o ato de escrever (ROJO, 2013). Isso ocorre devido ao novo contexto tecnológico vigente, no qual temos as tecnologias digitais influenciando diretamente na produção dos múltiplos sentidos, que emergem das formas diferenciadas pelas quais os textos se apresentam, e essas interferem na percepção individual do sujeito leitor (BAKHTIN, 2010).

Dentro dessa ampla - e nova - possibilidade de construção de sentidos, dentre os vários fatores existentes, destacam-se dois: o suporte e a esfera de atividade humana. Acrescente-se a esses o fato de termos uma multiplicidade de gêneros discursivos que circulam nessas esferas, alteram-se, hibridizam-se, (re)constroem-se, de acordo com as necessidades interacionais humanas (BAKHTIN, 2010), adquirindo as mais diversificadas formas textuais (ROJO,2013).

Desse contexto de uma língua viva, dinâmica e multifacetada, emerge 0 objetivo deste trabalho, focado na investigação da leitura e da literatura no contexto atual. Enquanto abordagem metodológica, elege-se a pesquisa qualitativa, a qual nos possibilita uma visão analítica sobre a leitura e o ensino de literatura, na escola pública, junto aos alunos-sujeitos do ensino médio.

Para percorrer tal caminho, organizamos o presente artigo da seguinte forma: iniciamos com uma breve retrospectiva do ensino de língua portuguesa, cônscios de que muitas ações atuais são reflexo do passado. A seguir, estabelecemos uma ponte entre a visão anterior e a atualidade, através dos Parâmetros Curriculares Nacionais de Língua Portuguesa (BRASIL, 1997; 1998). Na sequência, adentramos no cerne de nossa pesquisa, o ensino da leitura, da literatura e das novas tecnologias na escola.

Para proceder tal investigação, discorremos acerca de nossos materiais e métodos, com a compilação do resultado da pesquisa efetuada em uma escola pública, zona oeste de Londrina, junto aos 31 alunos que cursavam o ensino médio. Os passos subsequentes foram a compilação, categorização e análise dos dados coletados e as nossas considerações finais. 


\section{Fundamentação teórica}

\subsection{O ensino da língua portuguesa no Brasil: retrospectiva histórica}

O objetivo desta seção é apresentar alguns dados que sintetizam o panorama inicial do ensino brasileiro, pois, conforme preconizado na seção anterior, temos um déficit histórico, em grande parte gerado pela origem do nosso processo educacional, enquanto colônia europeia.

A implantação do sistema educacional brasileiro seguiu a mesma estrutura do ensino de Portugal, pois "[...] a língua portuguesa foi 'transportada' para cá, começando a ser 'falada' em um novo 'espaço-tempo'" (SILVEIRA; GUERRA JUNIOR; LIMOLI, 2012). Logo, à medida que passou a ser usada, a língua foi adquirindo, paulatinamente, novas características, o que é natural, considerando-se que seus falantes estão sujeitos a outras mediações. Assim, até meados do século XVIII, ser alfabetizado era sinônimo de ser letrado, e ler e escrever se restringiam a meramente ser alfabetizado, "[...] aqueles poucos alunos que tinham acesso a uma escolarização mais prolongada passavam diretamente à aprendizagem do latim, basicamente da gramática da língua latina e ainda da retórica e da poética" (SOARES, 2001, p. 1).

Em 1759, com a Reforma Pombalina, tivemos a obrigatoriedade do ensino de português, tanto no Brasil como em Portugal, assim "[...] ele definiu-se e realizou-se como ensino da gramática do português, ao lado do qual manteve-se, até fins do século XIX, o ensino da retórica e da poética" (SOARES, 2001, p. 1).

O modelo tido como padrão de colégio brasileiro era o Colégio D. Pedro II, criado em 1837, no Rio de Janeiro. Nesse momento, temos uma mudança significativa na grade curricular, pois ocorre a inclusão das disciplinas de retórica e poética, contemplando o ensino literário (literatura). No ano seguinte, 1838, tivemos a gramática nacional como objeto de ensino, conforme consta no regulamento do próprio colégio.

As disciplinas de retórica, poética e gramática surgiram no fim do império, e, em meados do século XIX, começou-se a empregar a nomenclatura "português". Em "1871, foi criado no país, por decreto imperial, o cargo de professor de português, e a disciplina português manteve, até os anos 40 do século $\mathrm{XX}$, a tradição da gramática, da retórica e da poética" (SOARES, 2001, p.1). 
Como podemos observar, houve uma mudança no objeto de ensino, impulsionada por alguns fatores: (i) o perfil dos alunos, pertencentes à classe privilegiada, com acesso à leitura e à língua culta; (ii) os professores possuíam uma consistente formação humanística e eram autodidatas; (iii) o objetivo dos docentes era 0 de que o aluno tivesse domínio das normas; para tanto, estudava-se o funcionamento dos textos literários, investigava-se a escrita e se procedia à sua análise. Com isso, tanto a retórica como a poética, paulatinamente, assumiram o caráter de estudos estilísticos, como hodiernamente conhecemos.

Outra mudança significativa ocorreu na década de 1950, com a inclusão dos filhos da classe trabalhadora na escola, momento em que, também consoante Soares (2001), o perfil do alunado começou a ser alterado. Uma década depois, nos anos 1960, o número de alunos que ingressava no sistema escolar chegou a triplicar, contudo, o domínio sobre a língua não acompanhava esse avanço. Segundo Fontes (1999), na década de 1950, o estruturalismo adentrou a escola e, com isso, o ensino gramatical e o literário, em nível de ensino médio, foram contemplados.

Consequentemente, à medida que tivemos o aumento do número de alunos na escola, houve maior demanda docente, que foi suprida por professores formados nas faculdades de filosofia, sobre as quais destacamos dois pontos: (i) tratava-se de faculdades recém-criadas, logo sem uma experiência consistente em ensino; (ii) a visão de linguagem vigente nessas faculdades era a mesma dessa época, ou seja, a linguagem como expressão de pensamento.

$\mathrm{Na}$ década de 1970, tivemos outra alteração significativa no contexto, pois ocorreu a entrada na escola dos filhos dos trabalhadores que residiam no campo (êxodo rural). Com isso, houve três mudanças significativas: (i) nova variante social adentra na esfera escolar (variação linguística); (ii) para atender à nova demanda, optou-se por privilegiar a quantidade em detrimento da qualidade; (iii) eliminou-se o exame de admissão para o ingresso no antigo ginasial ${ }^{5}$, que servia como uma espécie de "prova de admissão" que dificultava o ingresso da classe sociocultural menos privilegiada, ampliando, assim, o acesso à escola.

\footnotetext{
${ }^{5}$ Atualmente, equivale ao $3^{\circ}$ e $4^{\circ}$ ciclos do Ensino Fundamental.
}

Revista Educação Online, n. 19, jun-ago 2015, p. 20-44 
Como houve alterações significativas no ensino de língua materna, ocorreu uma busca por novas teorias que viessem ao encontro das novas demandas apresentadas. Consonante a isso, Perfeito (2005, p. 20) assevera que

O Estruturalismo, a teoria da comunicação, o estudo das funções da linguagem serviram de fundamento na produção de um modelo de ensino de Língua Portuguesa, enfatizado, a partir da promulgação das Leis de Diretrizes e Bases 5692, de 1971, no Brasil. A Língua Portuguesa, no ensino de 1ำ grau, passa a integrar, como carro-chefe, a área de Comunicação e Expressão, aí incluídas as disciplinas de Educação Física, Educação Artística e Língua Estrangeira. Integração esta quase inexistente na prática.

Nesse momento, predominava a concepção de linguagem enquanto instrumento de comunicação, sendo a língua vista como um código (emissor, receptor), dentro de uma visão a-histórica, ou seja, isolada de seu uso social. Porém, no desenvolvimento da sociedade, surgiram os meios de comunicação de massa e, na escola, ampliava-se o trabalho docente, contemplando a leitura de textos não literários e, embora ainda timidamente, o trabalho com a produção textual. A justificativa dessa ampliação é sedimentada no objetivo da escola vigente, isto é, o aluno é capaz de "expressar com eficiência as mensagens - falar e escrever" (SOARES, 2001) Nessa visão, o eixo de articulação e progressão que prevalece é o ensino gramatical. Assim, o estudo das funções da linguagem e dos elementos da teoria da comunicação foi privilegiado. As asserções de Perfeito (2005, p. 20) contextualizam esse período educacional:

Somando-se ao dito, predominava à época, no país, a concepção tecnicista de ensino (período de consolidação da ditadura militar, iniciada em 1964). Na concepção tecnicista de ensino, a visão de reforço é acentuada, pois a aprendizagem é vista como processada pela internalização inconsciente de hábitos (teoria comportamentalista/behaviorista).

Somente com o desenvolvimento de novas teorias linguísticas ${ }^{6}-$ a partir da década de 1980 - é que vamos encontrar a alteração tanto da concepção de linguagem como do objeto de ensino de língua portuguesa. Dessa forma, a linguagem passou a ser concebida como meio de interação ${ }^{7}$, e o signo, visto - na

\footnotetext{
${ }^{6}$ Teoria da Enunciação de Benveniste, a Pragmática, a Semântica Argumentativa, a Análise da Conversação, a Análise do Discurso, a Linguística Textual, a Sociolinguística, a Psicolínguística, a Linguística Aplicada, a Enunciação Dialógica de Bakhtin (SOARES, 2001).

7 Destacam-se, nesse período, as contribuições da psicologia da aprendizagem para os estudos interativos, investigando a relação sujeito-objeto-ensino (Piaget), bem como a questão dos estudos sobre a questão da mediação do sujeito, por meio de signos (Vygotsky).
}

Revista Educação Online, n. 19, jun-ago 2015, p. 20-44 
nossa concepção - enquanto socialmente ideológico. É nessa perspectiva que o presente trabalho se inscreve.

\subsection{O ensino da língua portuguesa no Brasil: visão atual}

Atualmente, vemos que essa busca por novos caminhos não tem uma voz uníssona, ao contrário, ela é referendada pela multiplicidade de vozes encontradas nos estudos de Marcuschi (2008), Fiorin (2001), Matêncio (1994), Soares (2001), Travaglia (1997), dentre outros, que referendam o posicionamento de que o ensino de língua materna precisa encontrar novas abordagens para o ensino gramatical.

Diante disso, estudos comprovam que a leitura e a escrita vêm sendo objeto de muitas reflexões. Contudo, a prática pedagógica nos aponta que, mesmo o aluno tendo acesso ao código linguístico, isso não está sendo suficiente para prepará-lo para as diversificadas situações comunicativas que ele enfrenta em sua vivência. Nota-se que há uma distância entre a realidade do educando e o conteúdo programático trabalhado nas salas de aula.

A problemática apresentada é comprovada por diversos estudiosos, dentre os quais destacamos Dolz e Schneuwly (2004), Matêncio (1994) e Geraldi (1993), que corroboram que há uma lacuna entre o que se ensina e o que seria necessário ensinar, e uma tentativa de mostrar novas possibilidades, ao professor e à sociedade, é apresentada através de propostas curriculares de estados e municípios, principalmente para os níveis fundamental e médio, que visam à obtenção de melhorias no ensino na escola pública.

Em uma tentativa de aprimorar a qualidade do ensino no quadro educacional brasileiro, houve o lançamento dos Parâmetros Curriculares Nacionais de Língua Portuguesa, doravante PCN (BRASIL, 1997; 1998). Nesses documentos, a linguagem é entendida como um trabalho coletivo, fruto das relações sóciohistoricamente construídas, com um papel essencial, devendo ser "uma ação orientada para uma finalidade específica [...] que se realiza nas práticas sociais existentes, nos diferentes grupos sociais, nos distintos momentos da história" (BRASIL, 1998, p. 20).

Há que se enfatizar que os PCNs são um documento oficial, que têm como objetivo servir como referência - não como um modelo - para os professores. Isso 
se justifica, uma vez que nosso país tem uma extensão territorial muito grande, e cada estado é portador de características específicas. Ainda assim, dentro de um estado, a realidade encontrada na cidade não é igual à da zona rural, da mesma forma que a vida em grandes centros não é igual à da periferia. Com essas reflexões, queremos frisar que realidades diferentes requerem tratamentos diferenciados.

Diante do exposto, embora tendo um documento como base, cada escola deverá reunir seus professores e elaborar um projeto político pedagógico que contemple as necessidades de seus educandos. Concluída essa etapa, tendo um direcionamento, cada professor poderá elaborar o conteúdo programático com o qual irá trabalhar.

Para que o trabalho do professor seja bem-sucedido, é importante observar que, em termos de ensino-aprendizagem em língua materna, os estudos que privilegiam a concepção dialógica de linguagem, apregoados pelos PCNs, são advindos da teoria bakhtiniana e foram iniciados por Geraldi (1984), ainda na década de 1980. Como proposta inovadora, o estudioso indicou um trabalho integrado, sem artificialidade, das práticas de leitura, análise linguística e de produção/refacção textual.

A notoriedade dos estudos do Círculo de Bakhtin, sobre o qual já versamos, desencadeou uma reação em cadeia, cuja consequência foi outra ação: a publicação de várias obras de pesquisadores/explicadores/interpretadores da teoria bakhtiniana, dentre os quais destacamos Brait (2005), Rodrigues (2005) e Rojo (2005), que possibilitaram que a teoria fosse contemplada em pesquisas universitárias, materializada através de obras renomadas ${ }^{8} \mathrm{e}$, paulatinamente, chegasse até o professor, adentrasse as salas de aula. Do construto teórico à sua prática, o professor necessita de explicadores que apontem como aplicar, pedagogicamente, atividades que contemplem os gigantescos e complexos pressupostos sobre língua, linguagem, alteridade, interação, dialogismo, dentre outros.

\footnotetext{
${ }^{8}$ Ornellas (2012), em nota de rodapé, explica que "pesquisadores brasileiros contam com uma oferta maior de obras sobre o pensador russo, tais como $A$ revolução bakhtiniana, do filósofo italiano Augusto Ponzio (2008), Beth Brait, que lançou os estudos Bakhtin: dialogismo e polifonia e Bakhtin e o Círculo, ambos de 2009, e também organizou as coletâneas Bakhtin: conceitos-chave (2005) e Bakhtin: outros conceitos-chave (2006). Brait republicou, em 2005, o então esgotado Bakhtin: dialogismo e construção do sentido. Organizada por Faraco e Tezza, está a coletânea Vinte ensaios sobre Bakhtin (2006)".
}

Revista Educação Online, n. 19, jun-ago 2015, p. 20-44 
A visão interativa da linguagem é tomada oficialmente, em termos nacionais, pelos Parâmetros Curriculares Nacionais de Língua Portuguesa no Ensino

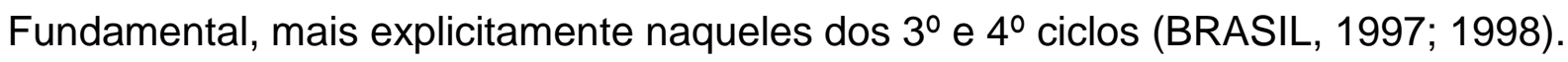
No documento, concebe-se a linguagem como forma de interação, o que significa entendê-la como um trabalho coletivo, portanto em sua natureza sócio-histórica (BRASIL, 1998, p. 20).

\subsection{O ensino da língua portuguesa no Brasil: leitura e literatura na escola}

Inúmeros trabalhos já foram realizados com a intenção de desvendar as relações entre leitura e literatura no espaço escolar. Muitas discussões foram empreendidas, e ainda não há um consenso nas questões que se referem à leitura, à literatura ou mesmo ao uso das novas tecnologias na escola. O discurso tem sido sempre o mesmo: "a leitura literária difícil, complexa e inacessível para os alunos" (SILVA, 2005, p.19). Se, subitamente, pedir-se a geração $X^{9}$ que descreva a primeira imagem que the vem à mente quando se fala em leitura, possivelmente teremos a figura cristalizada de um adulto com um livro na mão, contanto uma história, tendo uma criança sentada em seu colo ou próxima a ele. Esse quadro era constante nos livros didáticos, permanecendo praticamente estanque há mais de três décadas.

Com o advento da tecnologia, nossa vida sofreu inúmeras transformações. Uma das preocupações que tem sido constante no ensino é como formar leitores, diante dos avanços tecnológicos, das transformações comportamentais dos jovens 'antenados' com as mídias sociais e ditadores de novas formas, para que busquemos caminhos para o "novo" leitor. A própria forma como as avaliações estão sendo direcionadas já nos impulsionam para esse pensar. É muito comum constar em provas diversas, textos que nos remetem à leitura e à literatura no contexto atual. Por isso, é preciso inovar nas técnicas, para atingir uma geração de jovens identificados como geração Z ou ainda os determinados "geração internética".

\footnotetext{
${ }^{9}$ Até pouco tempo atrás, livros e filmes ainda falavam da Geração X, aquela que substituiu os yuppies dos anos 1980. Essa turma preferia o bermudão e a camisa de flanela à gravata colorida e ao relógio Rolex, ícones de seus antecessores. Isso foi no início dos anos 1990. Recentemente, o mercado publicitário saudou a maioridade da Geração Y, formada pelos jovens nascidos do meio para o fim da década de 1970, que assistiram à revolução tecnológica. Ao contrário de seus antecessores slackers - algo como "largadões", em inglês -, os adolescentes da metade dos anos 1990 eram consumistas. Mas não de roupas, e sim de traquitanas eletrônicas. Agora, começa-se a falar na Geração Z, que engloba os nascidos em meados da década de 1980. (<http://veja.abril.com.br/idade/exclusivo/jovens/apresentacao.html>. Acesso em 10/12/2014)
}

Revista Educação Online, n. 19, jun-ago 2015, p. 20-44 
Nesse sentido, Hannigan (2010, s/n) investigou o fator motivador do desinteresse dos jovens pela leitura em livros, e suas enunciações nos indicam que

Parte do meu completo desinteresse (pelos livros) vem do fato de que, no segundo em que um livro é publicado hoje, já está obsoleto. Desde que eu estava na quinta série, era capaz de acessar qualquer informação na internet de forma mais rápida e precisa do que conseguiria fazer em um livro. Além disso, a informação on-line é gratuita (e se não for, você vai procurar em outro site até encontrar "de graça"). Com um orçamento restrito e recursos grátis ilimitados, existe algum tipo de livro que poderia atrair meu interesse? (HANNIGAN, 2010, s/n)

$\mathrm{Na}$ citação acima, as proposições são direcionadas aos nascidos nos anos 2000. Trata-se dos adolescentes de hoje, 'antenados' com as mudanças tecnológicas e possuidores de certo poder aquisitivo, fruto de uma geração que começa a trabalhar cedo, visando à própria independência financeira, na busca pela aquisição dos seus objetos de desejo, tais como smartphones, notebooks, tablets, ipod, ipad, dentre outros.

Ocorre que esses objetos estão se tornando 'descartáveis', devido a forma acelerada com que são aperfeiçoados, devido ao rápido desenvolvimento tecnológico. Assim, tem-se uma nova necessidade: a troca. A justificativa dessa ação sedimenta-se na "onda" de acompanhar e adquirir as mesmas tecnologias utilizadas pelo grupo ao qual eles pertencem/participam, no intuito de haver maior identificação social.

Nesses grupos sociais, a comunicação se torna cada dia mais intensa e constante, em tempo real, altamente motivada pelas facilidades proporcionadas por esses "brinquedos" e pelos diversificados programas de troca de mensagens que se renovam, remodelam constantemente, como, por exemplo, o Facebook, o WhatsApp, possibilitando ainda mais a interação entre as pessoas sem sair de casa (ROJO, 2013).

Trata-se de uma geração de adolescentes conectados 24 horas por dia às redes sociais, por conseguinte, as notícias dos grupos sociais nos quais estão inseridos chegam até eles em tempo real. A rapidez na comunicação os deixa extasiados, pois podem criar espaços imaginários e simbólicos de ter, ser, de poder. Por conseguinte, essas novas mídias transformaram os hábitos de leitura dessa geração.

Não basta mais a escola enfatizar os letramentos da letra e os gêneros discursivos da tradição e do cânone. É urgente enfocar os multiletramentos e os novos letramentos que circulam na vida contemporânea de nossos alunos. [...] Os "cenários

Revista Educação Online, n. 19, jun-ago 2015, p. 20-44 
futuros" (ou presentes) para as escolas devem incluir a leitura e a escrita de gêneros de texto multissemióticos ou multimodais (compostos por todas as linguagens, para significar e funcionar) e os multiletramentos e novos letramentos requeridos pelas práticas em que estão inseridos (ROJO, 2013a, p. 19)

Segundo Rojo (2013a, p. 9), da mesma forma que a escola alfabetizava para ensinar a assinar o nome, ler pequenos textos (no século XIX) e depois, textos mais complexos (século XX), agora, é preciso é preciso "letrar para esses novos textos que se valem de várias linguagens". É preciso lembrar sempre que os gêneros que estão na Internet, como em sala de aula, misturam culturas o tempo todo, e, enquanto um gosta de ler na Internet, outro busca a leitura do clássico também no papel.

Isso se verifica, voltando ao texto de Hannigan (2010), quando a autora, ao final, questiona a si mesma dizendo: "existe algum tipo de livro que poderia atrair meu interesse?", ao que responde:

[...] sim. Em uma aula de marketing de nível superior, foram indicados três livros [...]. Eu pedi esses livros on-line, porque a livraria não tinha em estoque, e, enquanto eu esperava a encomenda, economizava para pagar, porque queria todos novos. [...] li esses livros de capa a capa [...] Todos eles oferecem informações abrangentes sobre as estratégias de marketing inovadoras, o que me mantém focado e me faz sentir como uma fonte. Quando leio esses livros, eu me sinto inteligente. [...].(HANNIGAN, $2010, \mathrm{~s} / \mathrm{d})$

Das asserções acima, depreendemos que ler é uma prática social, é um comportamento adquirido inicialmente na cultura familiar e, depois, ao longo das aprendizagens felizes (SOARES, 2001). Nos estudos de Marinho \& Silva (1998, p. 64), os pesquisadores descrevem que o leitor apresentado por Proust: "é leitor antes mesmo de abrir o livro". Essa relação é citada, porque a leitura de um livro se faz pela capa, pelo título, pelo autor, conhecendo as orelhas, a contracapa, identificando cada parte do livro, fazendo associações com outros, enamorando-se.

Para ser um leitor é preciso ter aguçada a curiosidade. Entra aí o papel do professor mediador, utilizando-se de diferentes técnicas, aproximando o aluno da leitura (VYGOTSKY, 1999; MORAN, 2012). Procurar livros com apelos visuais, temas que aproximem o leitor de suas vivências, linguagem atrativa e considerando que "ser leitor é uma questão de postura e de hábito" (MARINHO; SILVA 1998, p.68).

No contexto anteriormente descrito, como fica a questão da tecnologia? No nosso entender, a tecnologia é uma ferramenta altamente atrativa. As mídias sociais Revista Educação Online, n. 19, jun-ago 2015, p. 20-44 
podem ser grandes aliadas na formação do sujeito leitor, colaborando na formação de uma nova geração de leitores, afinal, o verbo ler não suporta o imperativo, reza a língua portuguesa. Já nos estudos de Rojo (2013a, p. 21), a autora reafirma tal ideia, quando diz que "é urgente enfocar os multiletramentos e os novos letramentos que circulam na vida contemporânea de nossos alunos".

Os PCNs (BRASIL, 1997; 1998), afirmam que a escola deve organizar-se em torno de uma política de formação de leitores. Todo professor, não apenas o de língua portuguesa, é também professor de leitura (BRASIL, 1998). Essa inferência de todos os professores se faz necessária, porque o jovem da geração $Y$ pode não ter a leitura como prioridade, contudo, é preciso desmistificar ideias cristalizadas, sobretudo quando se enuncia que a geração atual não lê ${ }^{10}$. Ao contrário, estudos apontam que nunca se leu tanto, em virtude da nova tecnologia, e esse contato assíduo tende a gerar um leitor voraz, visto que ele passa grande parte do seu tempo lendo, porém, suas leituras são de diferentes formatos (ROJO, 2013).

Para Levy (2003), o leitor de hipertexto é mais ativo do que o leitor de impressos, porque, antes de efetivar a leitura em tela, precisa interpretar as ações e comandos a serem enviados ao computador, para que, dessa forma, haja a projeção do texto. Os dados da Pesquisa Brasileira de Mídia $2014^{11}$, que revelam os Hábitos de Consumo de Mídia da População Brasileira, apontam que:

[...] a internet como o meio de comunicação que mais cresce entre os brasileiros; um quarto da população já acessa a rede diariamente, com uma intensidade média de 3h39 minutos por dia; crise da mídia impressa é total: $75 \%$ dos entrevistados afirmaram que não leem mais jornais; mídia mudou de forma veloz, radical e irreversível. (BRASIL, 2014, s/n)

A nova geração demonstra um potencial muito grande, relacionado ao fator curiosidade, e a busca de informações tende a acontecer através das ferramentas mais ágeis, como a Internet. Inclusive, eles tendem a buscar conhecimento com certa autonomia, sendo bons aprendizes e autodidatas (ROJO, 2013). Contudo, isso não é suficiente para os tornar leitores literários. Então, quando eles descobrem o texto literário, quando buscam informações sobre filmes, games e jogos, o encontro

\footnotetext{
${ }^{10}$ Conforme informação disponível em:

<http://www.brasil247.com/pt/247/pernambuco247/21325/Ap\%C3\%B3s-Cresp\%C3\%BAsculo-osjovens-est\%C3\%A3o-sim-lendo-mais.htm>. Acesso em 10/12/2014

1 A pesquisa é um levantamento nacional realizado pela Secretaria de Comunicação Social da Presidência da República, publicada em fevereiro de 2014 e disponível em: $<$ http://www.secom.gov.br. >. Acesso em 10/12/2014.
}

Revista Educação Online, n. 19, jun-ago 2015, p. 20-44 
os seduz, e a apresentação do texto literário para o aluno, mesmo que de forma compacta, tem como resultado a contribuição para a leitura, o que pode ser potencializado com a mediação do professor.

Ensinar com as novas mídias será uma revolução se mudarmos simultaneamente os paradigmas convencionais do ensino, [...] A Internet é um novo meio de comunicação [...]que pode ajudar a rever, a ampliar e a modificar muitas das formas atuais de ensinar e aprender. (MORAN, 2012, p. 63)

A literatura não está desvinculada da leitura, apesar de Sanches Neto (2013, p. 91) afirmar que "qualquer professor atento percebe que os calouros de letras, na sua grande maioria, chegam ao curso ainda sem intimidade com a leitura de textos literários". E isso se observa tanto no ensino público quanto no privado, sendo esse ainda mais voltado para um ensino focado no vestibular.

Para Zilberman \& Silva (2008, p.25) "a leitura deve vir na frente como um carro chefe, o desejo de reconstruir, de recriar, [...] o real inusitado informado pelo escritor", logo, observa-se que o conhecimento brota da interação leitor/texto literário, não sendo possível ensinar literatura sem essa relação, sem esse encontro, sem essa busca de sentidos que vão construindo significados e tornando-os compreensíveis diante do mundo em que se vive. Os autores afirmam que

[...] em termos sociais amplos, o sujeito necessariamente se educa ao fruir ou experimentar textos literários diversos. [...], pois nem todo ensino - principalmente 0 de cunho formal, escolarizado - facilita a fruição pelo aluno-leitor, de aspectos educativos que podem emanar ou resultar da leitura de textos literários. (ZILBERMAN \& SILVA, 2008. p.55).

Diante disso, percebe-se que o leitor literário deve saber escolher suas leituras, e a formação desse saber passa pela escola. Assim, segundo a autora: "o ensino de literatura se dá através da reintrodução da leitura da obra literária no contexto da sala de aula". (ZILBERMAN, 1993, p. 21). Todavia, temos uma questão: como é possível tal processo quando não há contato com o texto? Como já citado anteriormente, esse contato, essa familiarização só é proporcionada pela mediação do professor (VYGOTSKY, 1999; MORAN, 2012). É ele quem tem que se apresentar como um leitor, diferente dos alunos, por já ter uma caminhada, ter um saber literário constituído, que lhe assegura o papel desse professor mediador, que promove a intenção, intervenção, ação e reflexão sobre leitura, instigando a curiosidade e contribuindo para a formação de alunos leitores e leitores literários (ZILBERMAN, 1993).

Revista Educação Online, n. 19, jun-ago 2015, p. 20-44 
Paulino \& Cosson (2009) corroboram com as asserções de Zilberman (1993) e Vygotsky (1999), pois concordam que o professor mediador precisa ir além do ensino da história e do gênero literário, ele precisa também compreender, aprender, significar, ressignificar esse ser leitor e se aventurar, desejosa e corajosamente, em leituras mais complexas, que proporcionem, a cada novo texto, ampliar a construção de sua visão de mundo.

Para Jouve (2012, p. 163), "os estudos literários também favorecem o espírito crítico. [...] em uma obra, as ideias, os valores, a visão de mundo são objeto de uma leitura", reafirmando que a mediação do professor tem papel único e é fundamental para a definição do que é literatura e da criação literária, e "em cada época, textos estranhos e atípicos nos mostram (ou nos lembram) que o ser humano continua sendo um universo com vasta extensão a explorar" (JOUVE, 2012, p. 165).

\subsection{O ensino da língua portuguesa no Brasil: novas tecnologias}

Na década de 1970, o Brasil começou a pensar sobre tecnologia e educação. Todavia, somente em 1984, foi implantado, pelo Ministério da Educação e Cultura, o Educom $^{12}$, em cinco universidades públicas. Ele tinha, resumidamente, os seguintes objetivos: (i) promover a criação de centros pilotos para o desenvolvimento de pesquisas sobre o uso do computador; (ii) a formação de professores do magistério da rede pública de ensino; (iii) e a produção de software educativo e consequentemente, o Projeto Formar ${ }^{13}$ para preparar professores multiplicadores (ANDRADE; LIMA, 1993).

Em 1989, surgiu o primeiro Programa Nacional de Informática Educativa (Proninfe); em 1996, criou-se a Secretaria de Educação à Distância (SEED) e o Programa TV Escola, o Programa Nacional de Informática na Escola (Prolnfo); em 2005, o Mídia e Educação; e mais recentemente o Programa Um Computador por Aluno.

Da teoria à prática, verifica-se que o governo brasileiro sempre esteve atento às novas tecnologias no ensino, apesar de esbarrar em questões como

\footnotetext{
12 Educom - O primeiro projeto público a tratar da informática educacional, implantado nas universidades federais de Rio de Janeiro, Minas Gerais, Pernambuco, Rio Grande do Sul e na Unicamp.

${ }^{13}$ Formar - Implementado em 1997, para formação de profissionais, para atuarem nos diversos centros de informática educativa dos sistemas públicos de educação.
}

Revista Educação Online, n. 19, jun-ago 2015, p. 20-44 
infraestrutura, subutilização, falta de fiscalização na aplicação do dinheiro público. As intenções são boas, porém, há grande dificuldades no momento de colocar em prática as ações definidas. Como exemplo, citamos o fato de o Prolnfo ${ }^{14}$ ainda não ter chegado em muitas escolas, e, em outras, os computadores continuam em caixas lacradas, por falta de estrutura física, elétrica e técnica para seu funcionamento.

Proporcionar mudanças, através das novas tecnologias na educação, é uma obrigação dos governantes deste país. As gerações que hoje frequentam as escolas nasceram na era digital, e a escola, os professores, precisam acompanhar essa evolução tecnológica e contribuírem para a formação de cidadãos críticos e criativos, conduzindo-os na construção do conhecimento. O papel fundamental do professor é de um orientador mediador, afirma Moran (2012, p. 56).

As mudanças esperadas pela multimodalidade no ensino caminham vagarosamente. Na sala de aula, o aluno ainda permanece muito tempo ouvindo, copiando, olhando sempre centrado no professor e, segundo Levy (1999, p. 159) "a maioria das competências adquiridas por uma pessoa no início do seu percurso profissional estarão obsoletas no fim de sua carreira". Se isso fosse reeditado hoje, possivelmente, esse tempo diminuiria consideravelmente. O Smartfhone, adquirido no início de um ano, tem sido substituído antes de completar 12 meses de uso. Os acontecimentos na área tecnológica têm ocorrido absurdamente rápido. A prática reflexiva na educação, baseada no tripé ação/reflexão/ação, exige que o professor dinamize e ressignifique a prática profissional em sala de aula. Na sociedade da informação, a comunicação tende a ser interativa, permitindo os hyperlinks e a hipertextualidade na relação com alunos na sala de aula pela prática criativa (ROJO, 2013).

$\mathrm{Na}$ busca para agilizar esse cenário, no novo Plano Nacional de Educação (PNE 2014/2020), o governo federal define a orientação das ações a serem realizadas no planejamento da próxima década, para a execução de um trabalho educacional articulado com os estados e municípios. Dentre as 20 metas definidas, pode-se destacar a Meta 2:

\footnotetext{
${ }^{14}$ Proinfo- É um programa educacional, com o objetivo de promover o uso pedagógico da informática na rede pública de educação básica. (< http://portal.mec.gov.br/index.php?ttemid=462>. Acesso em 10/12/2014.
}

Revista Educação Online, n. 19, jun-ago 2015, p. 20-44 
universalizar o ensino fundamental de 9 (nove) anos para toda a população (Estratégia 2.4); desenvolver tecnologias pedagógicas que combinem, de maneira articulada, a organização do tempo e das atividades didáticas entre a escola e o ambiente comunitário, considerando as especificidades da educação especial, das escolas do campo e das comunidades indígenas e quilombolas. (Brasil 2014)

Na Meta 16, o governo retoma a proposta de atuar na formação de professores, mais especificamente, volta-se para a educação básica, visto que tem a intenção de "formar em nível de pós-graduação, 50\% dos professores da educação básica, até o último ano de vigência deste PNE", e garantir a todos(as) os(as) profissionais da educação básica formação continuada (BRASIL, 2014). No que tange à Estratégia 5.1, ainda com referência à Meta 16, destaca estar "proposto o fomento ao desenvolvimento de tecnologias educacionais e de inovação das práticas pedagógicas".

Apesar de adiar por mais 10 anos, cria-se uma expectativa de mudanças, que proporcionem novos caminhos para o ensino, diante das novas tecnologias e multimodalidades, o que é defendido desde 2012 por Moran (2012), tanto que o autor destaca a relevância dessa ação, "se quisermos ser eficientes e eficazes no processo educacional" (p.171).

Assim, tendo discorrido acerca da relevância de se contemplar as novas tecnologias no ensino, em busca de um mapeamento da realidade escolar londrinense, propomo-nos a ir a campo, em sala de aula, investigar a temática, conforme apresentaremos na seção subsequente.

\section{Materiais e métodos}

Os materiais e métodos nesta seção citados fazem parte da dissertação de mestrado, que tem por objetivo investigar a relação entre a leitura, a literatura e as novas tecnologias na escola, no contexto atual. Logo, os dados apresentados na próxima seção devem ser lidos como um recorte de uma pesquisa maior, que se encontra em fase de categorização, análise, para posterior cruzamento de dados.

Optou-se por uma pesquisa de cunho qualitativo-interventivo, considerando que a investigação foi feita in loco, em uma série específica, ou seja, $3^{\circ}$ ano do ensino médio, turno da manhã, de uma escola pública. Além disso, não houve uma preocupação com a quantificação de dados, mas com a sua qualificação. 
Nesse sentido, a abordagem qualitativa adota o paradigma interpretativista, visto que privilegia a interpretação dos dados, considerando-se o contexto, as práticas sociais e ampliando a capacidade do pesquisador. Ele se coloca como um agente ativo, preocupado com a investigação que visa à compreensão dos fenômenos; logo, para desenvolver esse olhar, ele se ancora nos paradigmas críticos (SIGNORINI, 2006).

Apesar de buscar a neutralidade na leitura dos dados, estamos cônscios da dificuldade dessa imparcialidade, pois, de acordo com Bortoni-Ricardo (2008, p. 58), a "pesquisa qualitativa reconhece que o olho do observador interfere no objeto observado, ou seja, o olhar de interpretação da realidade com a qual se defronta".

A escola selecionada se localiza na cidade de Londrina, zona oeste, e o fator motivador para que o trabalho fosse ali desenvolvido foi a disponibilidade da professora, aceitando a proposta e proporcionando ao pesquisador desenvolver atividades que contemplassem o ensino da leitura e literatura, em virtude da realização do vestibular.

Antes de adentrarmos a sala de aula, realizamos reuniões com a professora, por meio das quais se fez um diagnóstico prévio da turma, analisou-se o currículo escolar e, após a verificação de algumas produções dos alunos e das avaliações, conjuntamente com a professora, foi possível mapear algumas demandas dos alunos e trilhar um caminho. Desse diagnóstico, depreendeu-se que temos 31 sujeitos de pesquisa.

Para o diagnóstico prévio, com os alunos, em sala de aula, contou-se com o uso da ferramenta questionário, contendo questões abertas e fechadas, que serão nosso objeto de investigação. Segundo Marconi \& Lakatos (2006), essa ferramenta de pesquisa é um eficiente instrumento de coleta de dados, por meio do qual temos uma série ordenada de perguntas - abertas e fechadas - que foram respondidas por escrito, na presença do pesquisador.

Para que esse instrumento - o questionário - fosse elaborado foi preciso: (i) investigação sobre a temática a ser estudada; (ii) selecionar as questões; (iii) limitar tanto a extensão quanto a finalidade; (iv) codificar, categorizar dados, para posterior tabulação; (v) explicitar os enunciados, de forma que o interlocutor os compreenda; (vi) ter uma apresentação estética adequada (MARCONI; LAKATOS, 2006). 
Os dados coletados por meio da ferramenta anteriormente descrita foram organizados, categorizados e serão nosso objeto de análise no item a seguir.

\section{Resultados e discussão}

Considerando que o enfoque deste trabalho é a relação entre a leitura, literatura e as novas tecnologias, iniciamos o questionário, perguntando qual era o sexo dos educandos, no intuito de, posteriormente, cruzarmos os dados coletados e vermos se haveria influência desse fator. Assim, nessa série, tivemos um equilíbrio, pois os dados indicam que, no universo de 31 alunos há 17 meninos, 52\%, e 16 meninas, o que representa $48 \%$. Ao investigarmos a faixa etária dos desses sujeitos, temos uma faixa que vai de 16 a 19 anos: 16 anos (5 alunos); 17 anos (23 alunos); 18 anos (2 alunos); e 19 anos (1 aluno).

Outro fator que investigamos, considerando o nosso diálogo entre o ensino e as novas tecnologias, estava relacionado à facilidade ou não do acesso que esses sujeitos têm aos computadores. A maioria, 97\%, ou seja, 30 alunos, têm acesso com tranquilidade, e apenas 3\%, o que representa 1 aluno, não tem acesso. A seguir, interessou-nos aprofundar a questão anterior, indagando de qual local o aluno acessava a Internet. Vejamos:

\section{Quadro 1: Local aonde o aluno acessa a Internet}

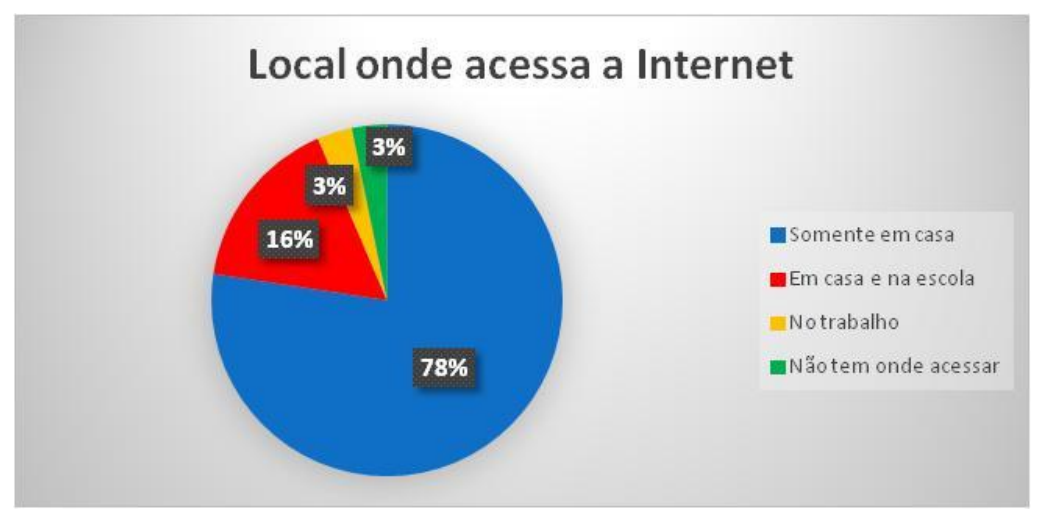

Fonte: Dados da pesquisa.

Como pode ser observado, pela leitura do gráfico, a casa ainda é o lugar no qual o aluno mais acessa a rede de computadores, com o total de $78 \%$. Na sequência, temos os alunos que têm acesso em dois lugares, ou seja, tanto em casa como na escola, com $16 \%$. Pessoas que acessam somente no trabalho perfazem o 
total de $3 \%$, e o mesmo percentual encontramos para os sujeitos que não têm um lugar aonde podem acessar.

Uma vez que investigamos o local em que o educando tinha acesso à rede de computadores, saber se ele o considerava tranquilo, isso nos apontaria que os provedores, por conseguinte, estavam conseguindo suprir as demandas apresentadas.

Diante disso, com relação à facilidade de acesso do educando à rede de computadores, os dados indicaram que a maioria - 90\% - acessa com frequência e com facilidade. Apenas 7\% asseverou que não considera esse acesso muito fácil nem muito constante, fator influenciado pela lentidão do provedor, conforme informado pelo sujeito da pesquisa; 3\% considerou como raro e difícil, o que é justificável, pois, no cruzamento dos dados, vimos tratar-se do educando que não tem acesso à Internet.

Após termos o dado real, ou seja, termos comprovado que a maioria fazia uso, em seu cotidiano, da Internet, decidimos investigar a navegação, isto é, com quais objetivos os alunos usavam a Internet. Por isso, nesta questão, não será possível nos restringirmos ao percentual de 100\%, uma vez que foi dada ao educando a opção de assinalar mais de uma alternativa. O resultado da compilação dos dados foi:

\section{Quadro 2: Com que finalidade o aluno faz uso do computador e da Internet}

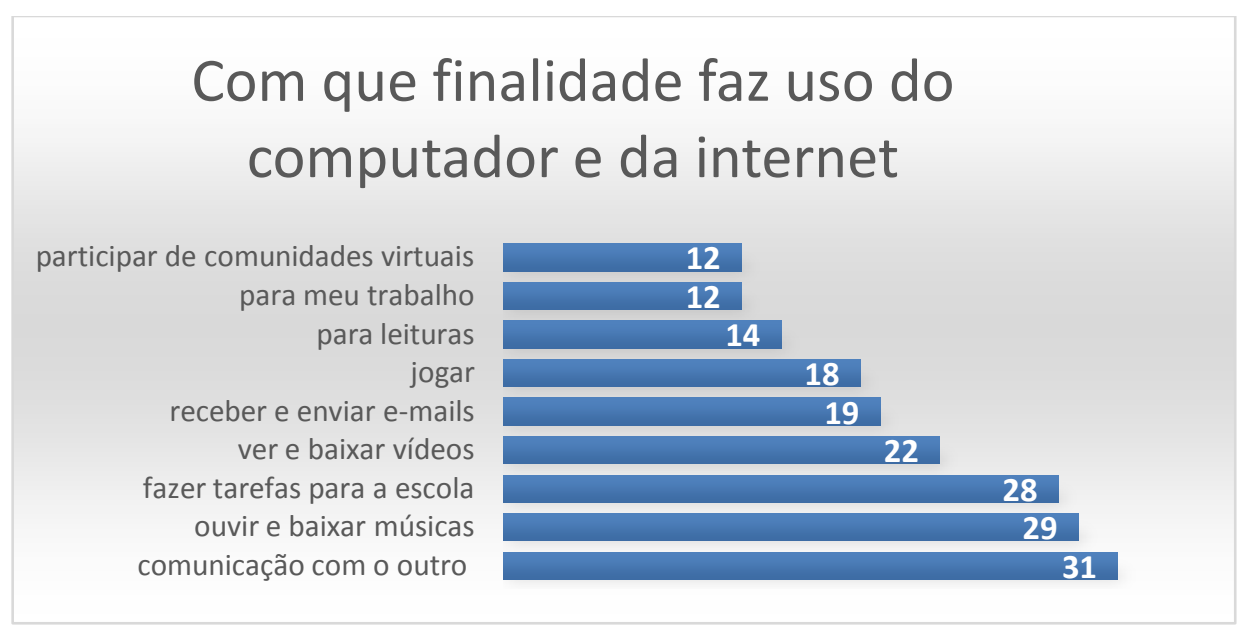

Fonte: Dados da pesquisa.

Pelas respostas dos sujeitos, no uso do computador, enquanto uma ferramenta, predominou o fator interação (comunicação com o outro); a seguir, vem 
o lazer (ouvir e baixar música); as pesquisas feitas para a instância escolar ocupam o terceiro lugar; assistir e baixar vídeos para entretenimento ficou em quarta posição; depois, temos o uso do e-mail, os jogos, as leituras, o trabalho e a participação em comunidades virtuais. Como foi deixada uma parte da questão aberta, para que eles pudessem escrever algo que não estivesse contemplado anteriormente, dois alunos fizeram os seguintes apontamentos: (i) assistir a vídeoaulas e filmes; (ii) ler artigos científicos e livros eletrônicos. Investigada a motivação para a leitura, os dados nos apontaram que 48\% leem por diversão/prazer; $39 \%$ pela necessidade de estudo e do trabalho; e 13\% por obrigação imposta pela escola.

Ainda sobre a leitura, foi indagado se o aluno gostava ou não de ler. Embora essa questão pareça ser simplista, é importante, sobretudo na fase do diagnóstico inicial, que o docente investigue se o seu sujeito de pesquisa tem prazer em ler. Essa resposta indicará possíveis relações prévias desenvolvidas com a leitura, ao longo de todo processo de ensino-aprendizagem. As enunciações proferidas indicam que a maioria - $71 \%$ - gosta de ler, e que apenas $29 \%$ não têm prazer em executar essa ação.

Diante do exposto, independentemente de o aluno gostar ou não de ler, vivermos em uma sociedade altamente grafemática, por conseguinte, 0 aprofundamento da questão anterior se faz necessário, a fim de investigar quais ferramentas são acionadas no momento em que ele pratica a ação de ler. Para tanto, formulamos a questão cujos dados apresentamos a seguir:

\section{Quadro 3: Qual ferramenta utiliza para acessar a Internet?}

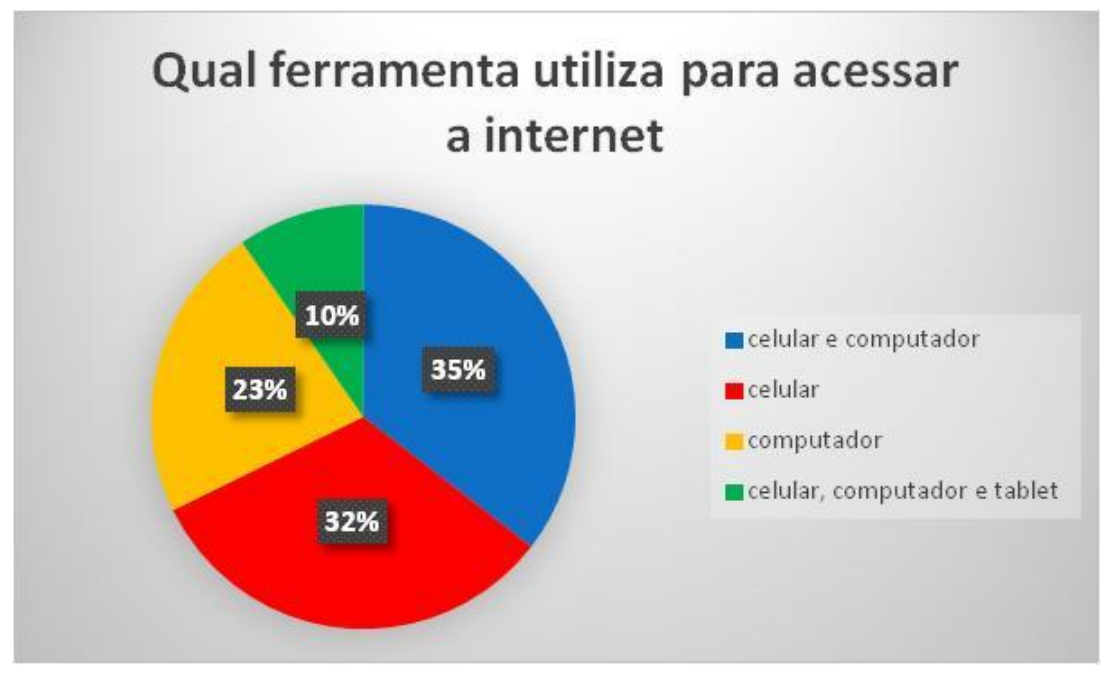

Fonte: Dados da pesquisa.

Revista Educação Online, n. 19, jun-ago 2015, p. 20-44 
De posse das respostas dos educandos, categorizamos e organizamos os dados, dos quais depreendemos que 35\% acessam a Internet através do celular e computador; $32 \%$ recorrem somente ao aparelho de celular; $25 \%$ limitam seu uso ao computador; o tablet é utilizado somente por $10 \%$ dos alunos pesquisados.

Moran (2012)] aponta que ter acesso às novas tecnologias requer uma série de fatores intrinsecamente associados, entre eles o aparelho físico e o provedor. Essa infraestrutura gera gastos financeiros e exige aprimoramento constantes, devido à rapidez com que essa área evolui.

Dando prosseguimento às pesquisas, já cônscios do grau de facilidade ou não de acesso à Internet, do local físico e da ferramenta utilizados (celular, computador, tablet), passou-se para a fase, na qual focamos o objetivo de esse sujeito navegar na rede. $O$ resultado nos aponta para os seguintes dados:

\section{Quadro 4: Finalidade pela qual o aluno acessa a Internet}

\section{Com que finalidade faz uso do computador e da internet}

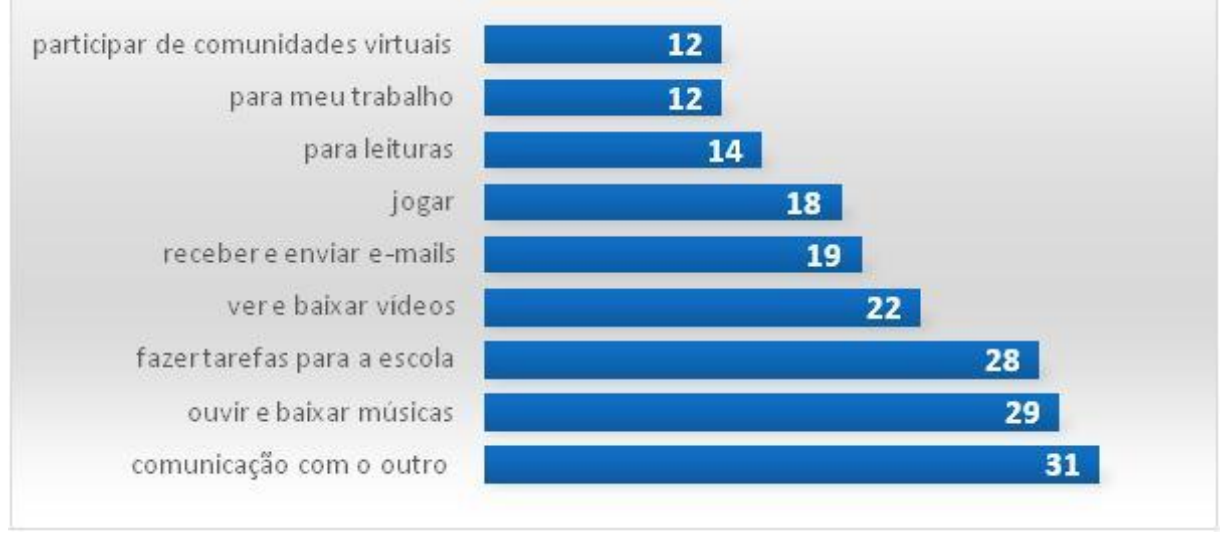

Fonte: Dados da pesquisa

Antes de procedermos à leitura dos dados, é preciso tornar a ressaltar que, nesta questão, também foi possibilitado ao aluno assinalar mais de uma opção, no caso das alternativas elencadas não contemplarem a realidade dele. Assim, pelo resultado, observa-se que a interação - comunicação com o outro - ficou em primeiro lugar, e, logo a seguir a ação de ouvir e baixar músicas e fazer tarefas da escola. Um pouco mais distante, ficou assistir filmes, receber e enviar e-mails e jogar. Nos 
últimos lugares, ficaram a leitura, o trabalho e a participação em grupos e/ou comunidades virtuais.

Isso posto, nos parece que a leitura ainda está sendo pouco explorada nessa modalidade midiática. Contudo, quando comparamos esses dados àqueles relativos ao meio que o aluno utiliza para ler, se a Internet ou o livro impresso, a primeira se destaca com $87 \%$ dos estudantes, enquanto o livro impresso, apenas $13 \%$, o que vem ao encontro dos estudos de Levy (2003). Esses dados nos permitem inferir que a leitura na Internet ainda prevalece sobre a leitura em livros. No entanto, quando cruzamos esse dado com os do gráfico anterior, vemos que o aluno está lendo relativamente pouco, uma vez que, no gráfico 8 , apenas $14 \%$ aparecem utilizando 0 computador para leitura.

Sobre a frequência de uso da Internet, $90 \%$ a acessa diariamente; $7 \%$, às vezes; e apenas 3\%, duas vezes por semana. Quando investigamos o gênero lido, obtivemos, pela ordem de preferência: (i) revistas; (ii) livros de literatura; (iii) textos da escola; (iv) gibis; (v) jornais. Dentro do gênero gibi destacou-se o mangá entre os meninos. No tocante aos livros de literatura, os mesmos não se limitaram às obras do vestibular, mas à literatura universal, incluindo livros de ficção, tais como os citados por eles: Harry Potter; Jogos vorazes; A culpa é das estrelas; O Hobbit; e as triologia Senhor dos anéis e A saga do crepúsculo.

Diante do exposto, entendemos que o interesse por muitas das obras citadas foi motivado pela indústria cinematográfica. Outro ponto a ser observado é que consideramos o fato de a literatura ocupar o segundo lugar como um ponto importante para o desenvolvimento, tanto da leitura, como da expansão da literatura na escola.

Por fim, para investigar a relação que o aluno tinha com a leitura, e mais especificamente com a literatura, foi solicitado que ele assinalasse as palavras que, a partir do seu conhecimento sobre o mundo, o fizesse considerá-las como literárias. Vejamos: 


\section{Quadro 5: Palavras que o aluno reconhece como pertencente à área da literatura}

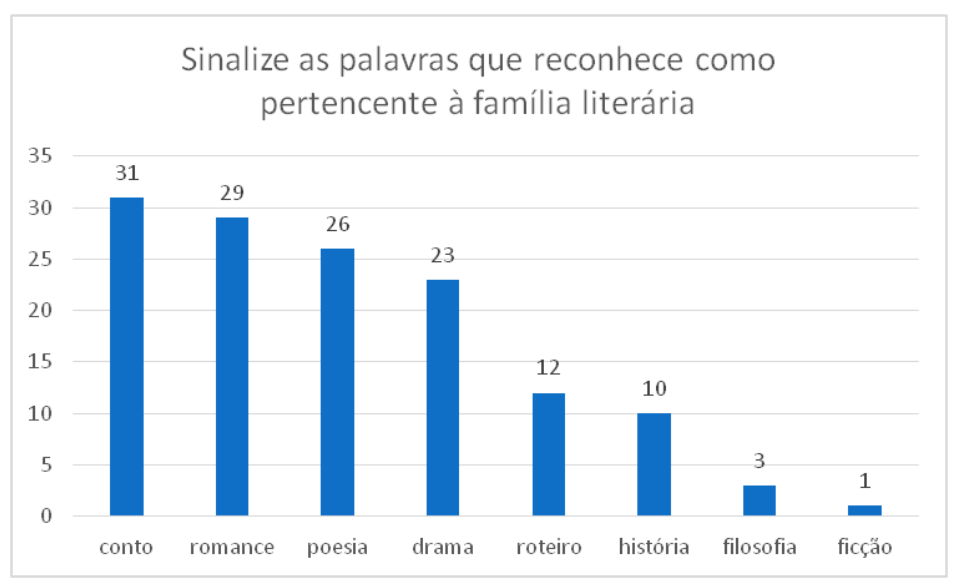

Fonte: Dados da pesquisa.

Quando a temática a ser investigada é a literatura, observamos que o universo linguístico disponível ao educando é muito amplo, pois a literatura envolve a vida (CÂNDIDO, 1985). Mesmo assim, o resultado dessa busca pelas palavras que remetem o aluno ao universo literário destacaram-se: (i) conto; (ii) romance; (iii) poesia; (iv) drama; (v) roteiro; (vi) história; (vii) filosofia e (viii) ficção. De fato, todo esse universo compreende as obras literárias, sobretudo a seleção lexical de "conto, romance e poesia", visto que são leituras mais próximas do cotidiano do educando.

Considerando que a seleção lexical é responsável pela construção de sentidos do texto, vimos que o aluno acessou seus conhecimentos prévios ao responder a questão, visto que todas as palavras têm uma relação direta com a literatura, logo, são plenamente coerentes para a situação discursiva proposta (GERALDI, 1993).

Enfim, após temos apresentado, mesmo que de forma concisa, uma compilação dos dados coletados junto ao ensino médio, escola pública, passemos as nossas considerações finais.

\section{Considerações finais}

Empreendemos nosso olhar nesta pesquisa pela busca por investigar a relação entre a leitura e a literatura na era atual, ou seja, em um momento sóciohistórico-cultural, no qual imperam as novas tecnologias. Entendemos como premente essa investigação, considerando que os alunos chegam à escola alfabetizados tecnologicamente, e o resultado desse contexto é o surgimento de um 
novo leitor, um leitor navegador, que apresenta hábitos distintos do leitor do texto impresso, que faz sua leitura linha/linha, página a página. O novo leitor navega em telas, salta de link em link, interage entre textos, imagens, músicas, vídeos, jogos etc.

Diante disso, o resultado da pesquisa na escola pública vem ao encontro dos estudos de Bakthin (2010), quando o autor destaca a influência do meio na produção, tanto de novos gêneros, como na alteração das necessidades de comunicação humana, pois os dados revelaram que: (i) a maioria dos alunos ainda acessa a Internet em seu lar; (ii) esse acesso é tranquilo para mais de $90 \%$ dos sujeitos e é realizado frequentemente e com facilidade; (iii) a interação prevaleceu enquanto objetivo central do uso do computador, seguido de lazer (música) e responsabilidades (tarefas escolares); (iv) o celular e o computador são as ferramentas que se destacam para o acesso à Internet; (v) a maioria dos alunos tem prazer em ler, contudo, essa leitura ocorre através do computador, ou seja, no texto digital, sendo o celular o objeto mais usado no universo pesquisado para a leitura.

Especificamente, no que tange à questão da leitura, da literatura e das novas tecnologias, o gráfico 5 indicou que os alunos reconhecem o universo literário, e as obras lidas por eles apontam que um fator sedutor para essa seleção parece ser a indústria cinematográfica. Isso se justifica, em parte, devido ao fascínio que a ficção exerce sobre estes jovens (como a série Senhor dos Anéis), em parte devido à extrema proximidade da literatura com as questões centrais da vida, dentre elas o amor, o ódio, o ciúme e a paixão, pois, conforme muito bem retrata Cândido (1985), a literatura é uma espécie de espelho da vida.

Por fim, porém não menos importante, encerramos este artigo com uma vírgula, no sentido de que outras leituras possam ser feitas sobre os dados coletados e destacando a relevância desse diálogo entre a universidade e a escola pública, sobretudo a importância da mediação do professor (MORAN, 2012; VYGOTSKY, 1999), visto que o resultado indicou um crescimento crucial na aprendizagem dos pesquisadores e sujeitos, envolvidos nas duas instâncias escolares. 


\section{Referências bibliográficas}

ANDRADE, P. F.; LIMA, M. C. M. Projeto EDUCOM. Brasília: MEC/OEA, 1993.

BAKHTIN, Mikhail M. Estética da criação verbal. 5aed. São Paulo: WMF Martins Fontes, 2010.

BORTONI-RICARDO, Stella Maris. O professor pesquisador: introdução à pesquisa científica. São Paulo: Parábola Editorial, 2008.

BRAIT, Beth (Org.). Bakhtin: conceitos-chave. São Paulo: Contexto, 2005.

BRASIL. Ministério da Educação e do Desporto. Parâmetros Curriculares Nacionais. 1ํ e 2o ciclos do ensino fundamental. Brasília, SEF, 1997.

. Ministério da Educação e do Desporto. Parâmetros Curriculares Nacionais. $3^{\circ}$ e 4ํㅡㄴ ciclos do ensino fundamental. Brasília: SEF, 1998.

. Planejando a próxima década. Brasília: Ministério da Educação/Secretaria de Articulação com os Sistemas de Ensino (MEC/SASE), 2014. Disponível em: $<$ http://pne.mec.gov.br/images/pdf/pne_conhecendo_20_metas.pdf>. Acesso em 07/12/2014

DOLZ, J.; SCHNEUWLY, B. Gêneros e progressão em expressão oral e escrita: elementos para reflexões sobre uma experiência suíça (francófona). Enjeux, p.3149, 1996. Tradução de R. H. R. Rojo. Circulação restrita.

GERALDI, João Wanderley (Org.). O texto na sala de aula. Cascavel: Assoeste, 1984.

1993.

. Portos de passagem. 4ª ed. São Paulo: Martins Fontes,

FIORIN, José Luiz. Curso de Letras: Desafios e Perspectivas para o próximo milênio. In: SEMINÁRIO NACIONAL DE LITERATURA E CRÍTICA E II SEMINÁRIO

NACIONAL DE LINGUÍSTICA E LÍNGUA PORTUGUESA, 4, 2001, Goiânia. Anais... Goiânia: Gráfica e Editora Vieira, 2001. p. 34-42.

HANNIGAN, Jeannie. Getting Gen-Y's Attention: 101, maio 2010. in: Disponível em $<$ http://www.thenextgreatgeneration.com/2010/05/genys-attention-101>. Acesso em 07/12/2014.

JOUVE, Vincent. Por que estudar literatura? São Paulo: Parábola, 2012.

LÉVY, Pierre. Cibercultura. São Paulo: Ed 34, 1999.

. O que é o virtual? São Paulo: Editora 34, 2003.

MARCUSCHI, Luiz Antônio. Produção de texto, análise de gêneros e compreensão. São Paulo: Parábola Editorial, 2008.

MARCONI, Marina de Andrade; LAKATOS, Eva Maria. Técnicas de pesquisa. 2ªed., rev. e ampliada. São Paulo: Atlas, 2006.

MARINHO, M; SILVA, C.S. da. Leitor interditado. Leituras do professor. Campinas: Mercado das Letras, 1998.

MATÊNCIO, Maria de Lourdes Meireles. Leitura, produção de textos e a escola: reflexões sobre o processo de letramento. Campinas: Mercado de Letras, 1994. 
MORAN, J. M.; MASETTO, M. T.; BEHRENS, M. A. Novas tecnologias e mediação pedagógica. Campinas: Papirus, 2012.

PAULINO, Graça e COSSON, Rildo. Letramento literário: para viver a literatura dentro e fora da escola. In: ZILBERMAN, Regina; ROSENG, Tânia M. K. (Orgs.). Escola e leitura: velha crise, novas alternativas. São Paulo: Global, 2009. p. 61-79.

PERFEITO, A. M. Concepções de linguagem, teorias subjacentes e ensino de língua portuguesa. In: SANTOS, A. R.; RITTER, L. C. B. (Orgs.). Concepções de linguagem e o ensino de língua portuguesa. Maringá: EDUEM, 2005. p. 27-80.

RODRIGUES, R. H. Os gêneros do discurso na perspectiva dialógica da linguagem: a abordagem de Bakhtin. In: MEURER, J. L.; BONINI, A; MOTTA-ROTH, D. (Orgs.). Gêneros: teorias, métodos e debates. $2^{a}$ ed. São Paulo: Parábola Editorial, 2005. p. 152-183.

ROJO, Hammes Rodrigues. Gêneros do discurso e gêneros textuais: questões teóricas e aplicadas. In: MEURER, J. L.; BONINI, Adair; MOTTA-ROTH, Désirée (Orgs.). Gêneros: teorias, métodos, debates. São Paulo: Parábola, 2005. p. 184-207. ROJO, Roxane. (Org). Escola conectada: os multiletramentos e as TICs. São Paulo: Parábola, 2013.

\section{Cenários futuros para as escolas. Educação no Século XXI. São}

Paulo: Fundação Telefônica, 2013.

Parábola, 2013.

. (Org). Escola conectada: os multiletramentos e as TICs. São Paulo:

SANCHES NETO, Miguel. O lugar da literatura: ensaios sobre inclusão literária. Londrina: Eduel, 2013.

SIGNORINI, Inês. Gêneros catalisadores letramento \& formação do professor. São Paulo: Parábola, 2006.

SILVEIRA, Ana Paula Pinheiro da; GUERRA JUNIOR, Antonio Lemes; LIMOLI, Loredana. A representação da linguagem em capas de gramática: uma abordagem Semiótica. In: SINGNUM: Estud. Ling., v. 15, n. 3 (esp.), p. 361-385, dez 2012.

SOARES, Magda. Que professores de português queremos formar. 2001. Disponível em: < http://www.filologia.org.br/viiisenefil/07.html> Acesso em 7/12/2014.

TRAVAGLIA, L. C. Gramática e interação: uma proposta para o ensino de gramática no $1^{\circ}$ e $2^{\circ}$ graus. São Paulo: Cortez, 1997.

ZILBERMAN, Regina. A leitura na escola. In: . (Org). Leitura em crise na escola: alternativas do professor. Porto Alegre: Mercado Aberto, 1993. p. 9-22.

; SILVA, Ezequiel Teodoro da. Literatura e pedagogia: ponto e contraponto. São Paulo; Campinas: Global; Associação de Leitura do Brasil, 2008. VYGOTSKY, Lev Semenovich. Pensamento e linguagem. São Paulo: Martins Fontes, 1999. 